\title{
Relação qualidade da água e fragilidade ambiental da Bacia do Rio Almada, Bahia
}

\author{
Gustavo Barreto Franco ${ }^{1 *}$, Luiza Silva Betim ${ }^{2}$, Eduardo Antonio Gomes Marques $^{2}$, \\ Ronaldo Lima Gomes ${ }^{3}$, César da Silva Chagas ${ }^{4}$
}

\begin{abstract}
Resumo Esta pesquisa teve como objetivo a criação do Índice de Qualidade da Água em Resposta à Fragilidade Ambiental (IQAFA) e a determinação dos níveis de fragilidade ambiental da Bacia do Rio Almada, Bahia. O mapa de fragilidade ambiental foi obtido a partir da integração das características: precipitação pluviométrica, substrato rochoso, declividade, solo e seu uso e ocupação, por meio de álgebra de mapas em ambiente de Sistema de Informação Geográfica na escala de 1:100.000. Foi classificado em cinco graus de fragilidade: Muito baixo, Baixo, Médio, Alto e Muito alto. As maiores fragilidades incluem as áreas urbanas, os sedimentos arenosos expostos na zona de praia, manguezais e bolsões degradados da planície costeira localizados na porção Leste e as áreas de pastagem e solo exposto nas porções Oeste da bacia. Nas classes que apresentaram fragilidade baixa estão incluídas as rochas do embasamento cristalino, recobertas pela floresta de mata atlântica e da cabruca. Os parâmetros utilizados (temperatura, condutividade elétrica, $\mathrm{pH}$, sólidos totais e turbidez) para o cálculo do IQAFA mostraram-se adequados, uma vez que as alterações da qualidade das águas refletiram a presença de áreas com menor ou maior valor de fragilidade ambiental, tornando-se uma ferramenta importante na compreensão da situação da qualidade da água frente a essa fragilidade. Ressalta-se que os resultados obtidos para o IQAFA foram validados por meio de correlações estatísticas com a fragilidade baixa e alta.
\end{abstract}

Palavras-chave: uso e ocupação do solo; sistema de informação geográfica; planejamento ambiental; Bacia do Rio Almada.

\begin{abstract}
Relationship water quality and environmental fragility of Almada River Watershed, Bahia, Brazil. The aim of this research is the creation of a Water Quality Index in Response to Environmental Fragility (WQIEF) and the determination of environmental fragility levels of Almada River Watershed, Bahia, Brazil. The environmental fragility map was generated from the integration of rainfall characteristics, geology, slope, soil, land use and occupation, through map algebra manipulated in a Geographical Information System. Fragility was divided into five degrees: Very low, Low, Medium, High and Very high. Major fragilities include urban areas, sandy sediments areas exposed at coastline, mangrove, degraded coastal areas located at East portion of study area; pasture areas and soil-exposed areas at West portion of the watershed. Low fragility classes include crystalline basement rocks covered by rainforest and Cocoa Agroecosystems. The parameters (temperature, conductivity, $\mathrm{pH}$, total solids and turbidity) used for the calculation of WQIEF were adequate, since changes in water quality reflected the presence of areas with higher or lower environmental fragility value, becoming an important tool in understanding the situation of water quality against the environmental fragility. It is noteworthy that the results obtained for WQIEF were validated through correlations with low and high environmental fragility.
\end{abstract}

Keywords: land use and occupation; geographic information system; environmental planning; Almada River Watershed.

\section{INTRODUÇÃO As interferências antrópicas} no meio físico têm sido motivo de apreensão nas últimas décadas, sendo crescente a preocupação com o sistema ambiental. Logo, as alterações nos diferentes componentes do ambiente, como o relevo, o solo e a cobertura vegetal, podem resultar no comprometimento da qualidade da água e da funcionalidade do sistema, alterando o seu estado de equilíbrio dinâmico, sendo esta intervenção maior ou menor em função das características intrínsecas do ambiente, ou seja, da fragilidade ambiental (Franco 2010).
O estudo integrado do meio físico, aliado à sua característica de uso e ocupação, permite obter um diagnóstico de diferentes categorias hierárquicas da fragilidade dos ambientes, tendo como produto sintetizador o mapa de fragilidade ambiental, que possibilita avaliar as suas potencialidades de forma integrada, compatibilizando características naturais com suas restrições. Assim, este mapa constitui uma ferramenta importante para o planejamento do uso e ocupação do solo, contribuindo com os órgãos públicos e privados na elaboração do planejamento físico-territorial.

\footnotetext{
${ }^{1}$ Universidade do Estado da Bahia - UNEB, Jacobina (BA), Brasil. E-mail: gustavopraia@yahoo.com.br ${ }^{2}$ Universidade Federal de Viçosa - UFV, Viçosa (MG), Brasil. E-mails: luizabetim@gmail.com, emarques@ufv.br ${ }^{3}$ Universidade Estadual de Santa Cruz - UESC, Ilhéus (BA). E-mail: rlgomes@uesc.br ${ }^{4}$ Empresa Brasileira de Pesquisa Agropecuária, Rio de Janeiro (RJ), Brasil. E-mail: chagas.rj@gmail.com

*Autor correspondente
} 
As bacias hidrográficas fazem parte de um complexo sistema ambiental em que os cursos d'água servem como indicadores da manipulação do solo pelo homem. Com isso, os rios que drenam uma região apresentam suas águas com características físico-químicas próprias, as quais refletem as pedológicas e geológicas da bacia e as atividades de uso do solo da região à montante. Deste modo, as bacias conferem um excelente campo para estudos de fragilidade ambiental, uma vez que seu estado de equilíbrio é capaz de ser facilmente modificado, com consequências que podem ser irreversíveis e refletirão na qualidade da água, dada a sua sensibilidade aos impactos.

Tendo em vista que a água do rio é o ponto de convergência do complexo sistema ambiental e que os parâmetros físico-químicos da água refletem o grau de fragilidade da área, elaborou-se o Índice de Qualidade da Água em Resposta à Fragilidade Ambiental (IQAFA). Para tanto, ele foi validado com os dados de fragilidade ambiental da Bacia Hidrográfica do Rio Almada (BHRA), localizada no estado da Bahia.

\section{MATERIAL E MÉTODOS}

\section{Objeto de estudo A área de estudo compre-} ende a BHRA (Fig. 1), parte integrante da Bacia do Atlântico Leste (Bahia 1996). A BHRA é uma bacia marginal que abrange área de $1.575 \mathrm{~km}^{2}$ e está localizada na região Sul da Bahia. Limita-se a Norte e a Oeste com a Bacia do Rio de Contas, a Sul com a Bacia do Rio Cachoeira e a Leste com o Oceano Atlântico e engloba áreas dos municípios de Almadina, Coaraci, Ibicaraí, Barro Preto, Itajuípe, Itabuna, Ilhéus e Uruçuca.

Como qualquer outra bacia que sofre interferência antrópica, ela apresenta alterações das suas condições naturais, dentre as quais se destacam: poluição dos mananciais hídricos; degradação dos solos e da cobertura vegetal; execução de obras de engenharia e atividades agropecuárias. Estes impactos merecem atenção em função da possibilidade de comprometimento da qualidade ambiental da BHRA, uma vez que estamos falando da principal fonte para o abastecimento público das cidades de Almadina, Barro Preto, Coaraci, Itabuna, Itajuípe e Uruçuca, considerada área para a implantação de diversas obras de engenharia, como porto, aeroporto e ferrovia, e constituída de belezas cênicas naturais, entre elas a Lagoa Encantada, remanescentes florestais de mata atlântica, sítios arqueológicos e paleontológicos.
A BHRA está inserida na região cacaueira da Bahia, local em que as formações florestais de mata atlântica foram mais conservadas devido ao modelo agrícola utilizado (cabruca). A adoção dele fez com que, ao longo de mais de 200 anos, se conservassem importantes fragmentos de floresta, fauna e solo, além dos recursos hídricos. Porém, desde a década de 1990, o cultivo do cacau sofre uma crise, cujas causas são a baixa dos preços no mercado internacional e o intenso ataque de uma praga conhecida como "vassoura de bruxa", que devastou grande parte da lavoura cacaueira. E devido a essa crise houve o abandono da monocultura e uma intensa derrubada de árvores, seja para a exploração comercial da madeira, seja para a implantação de pecuária extensiva.

\section{Compilação e tratamento de dados secundários}

Inicialmente, realizou-se o levantamento de informações sobre precipitação pluviométrica, substrato rochoso, solo e de seu uso e ocupação. Essas informações foram tratadas em ambiente de Sistema de Informação Geográfica (SIG), por meio do software ArcGis Desktop 9.3.

O mapa de precipitação pluviométrica, na escala de 1:100.000, foi digitalizado do trabalho de Roeder (1975). E o mapa de substrato rochoso da BHRA, na escala de 1:100.000, baseou-se, inicialmente, no levantamento da documentação existente referente à geologia da região, por meio do Programa de levantamentos geológicos básicos do Brasil, Itabuna - Folha SD-24-Y-B-VI (Arcanjo et al. 1997) e do mapa geológico do Estado da Bahia (Barbosa \& Dominguez 1996), em observações em imagens de satélite, principalmente para a consolidação das áreas de fundo de vales e baixadas litorâneas, e em trabalhos de campo realizados com o objetivo de validação das unidades mapeadas.

Para a geração do mapa de declividade, utilizaram-se os dados do TOPODATA com resolução de $30 \mathrm{~m}$, da folha 14_405_SN. Escolheu-se a opção slope do Spatial Analyst do ArcGis Desktop 9.3. Com base nessa imagem, foram extraídas as classes de declividade (em porcentagem).

O mapa de solo foi elaborado levando em conta duas fontes distintas: uma primária e outra secundária. Especificamente para o estudo proposto, foram feitos levantamentos de campo, na escala 1:50.000, por meio do método do caminhamento livre (Santos et al. 1995). A partir disso, as áreas foram intensamente percorridas de modo a identificar pontos de 


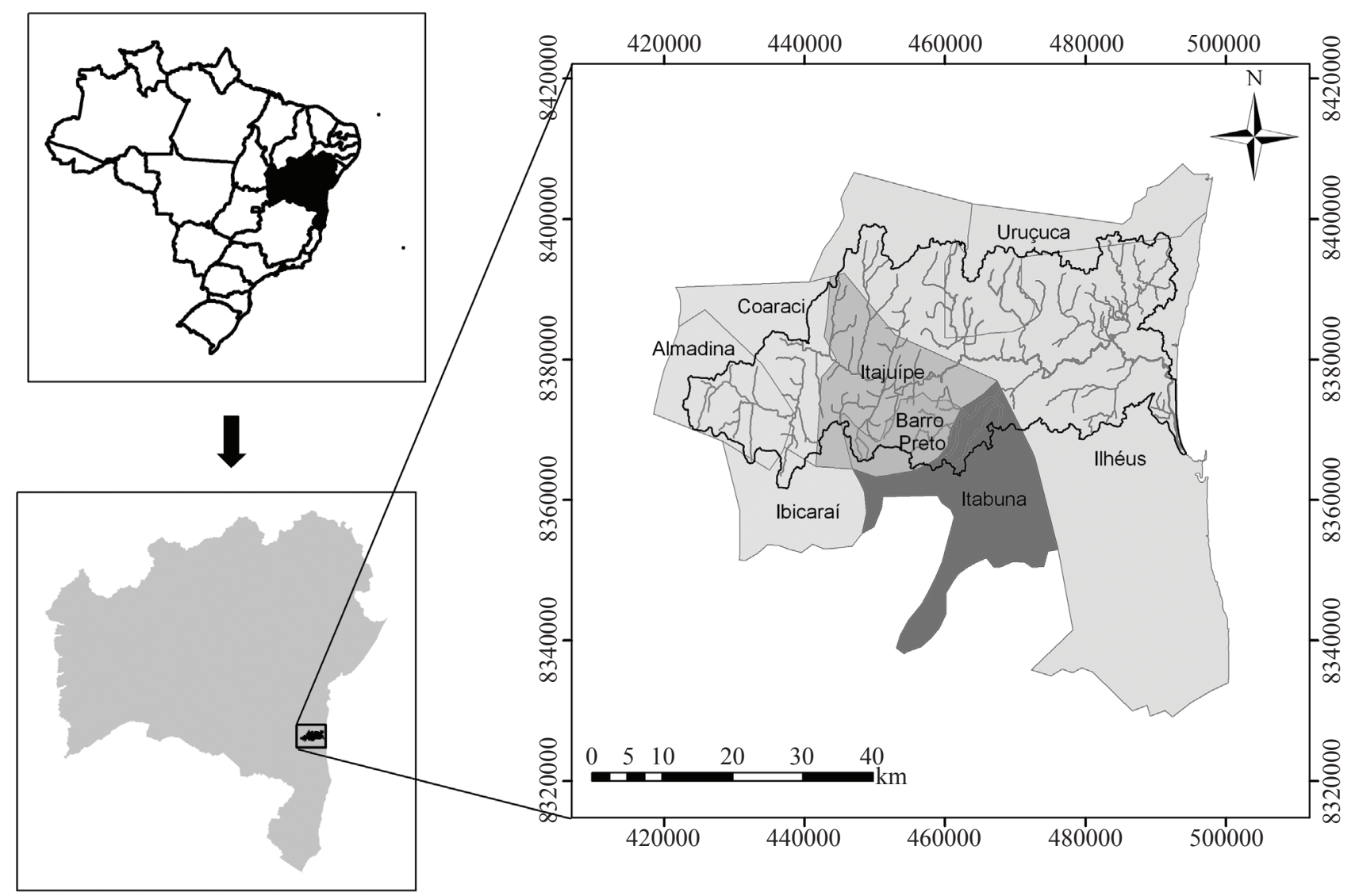

Figura 1 - Localização da Bacia Hidrográfica do Rio Almada, na Região Sul da Bahia.

observação em locais representativos, nos quais se coletou o máximo de informações para a caracterização dos solos no campo. Nessa etapa foram descritos e angariados 30 perfis de solos de acordo com os critérios estabelecidos por Santos et al. (2005). Os perfis de solos amostrados foram classificados segundo o Sistema Brasileiro de Classificação de Solos (Embrapa 2006), seguindo critérios morfológicos, químicos, físicos e mineralógicos.

Adicionalmente, dados obtidos em levantamentos de solos pré-existentes, realizados pela Comissão Executiva do Plano da Lavoura Cacaueira (CEPLAC) e outros órgãos em municípios inseridos na BHRA, foram utilizados, a saber: 12 perfis de solo do trabalho de Melo (1985), 7 de Santana et al. (1986), 2 de Santana et al. (1987), 6 de Carvalho Filho et al. (1987), 2 de Gomes (2002) e 1 do projeto Radambrasil (1981), que foram reclassificados para o Sistema Brasileiro de Classificação dos Solos (Embrapa 2006).

Ao todo foram utilizados 60 perfis de solos e 125 observações com informações do tipo de classe de solo e descrição da paisagem. A distribuição regional foi interpretada no contexto da paisagem, buscando relacionar os diferentes solos com os demais componentes do meio físico, principalmente o substrato rochoso e o relevo.
O mapa de uso e ocupação do solo da BHRA foi elaborado a partir de uma imagem do sensor TM do Landsat 5, 2006, utilizando as cenas 215/70 e 216/70. Aplicou-se o melhoramento do aspecto visual da imagem pela metodologia proposta por Richter (2000), com a remoção dos efeitos da atmosfera devido à absorção e dispersão da luz (correção atmosférica), no software Erdas 9.2. A correção atmosférica possibilitou melhor classificação da imagem e diferenciação dos alvos presentes, tornando-se, assim, possível diferenciar áreas de mata, cabruca, pastagem/cultivo de subsistência, restinga, solo exposto, área úmida, área urbana e corpos hídricos, devido às diferenças de espectros e reflectâncias. Foi utilizado o método de classificação supervisionada a partir da retirada de amostras espectrais da imagem. No ambiente do software Erdas 9.2, usaram-se os módulos Signature Editor e Aol Tool da versão ERDAS imagine 9.2. A diferenciação das classes de uso e ocupação foi autenticada pelas diferenças do nível de reflectância.

Vale ressaltar que o reconhecimento das amostras espectrais da imagem contou ainda com o conhecimento das áreas nas visitas a campo, bem como das características levantadas na caracterização da área de estudo e, por fim, da sua validação em campo. 


\section{Elaboração do mapa de fragilidade ambiental}

$\mathrm{Na}$ avaliação da fragilidade ambiental da BHRA foram utilizadas informações provenientes das características de precipitação pluviométrica, do substrato rochoso, da declividade, do solo e do seu uso e ocupação, considerando o grau de sensibilidade de cada um destes atributos.

Estabeleceu-se a hierarquização das classes dos atributos de cada plano de informação de acordo com o seu grau de fragilidade. A cada classe foi atribuído um índice numérico de 1 a 5 - designado em: Muito baixa, Baixa, Média, Alta e Muito Alta - a partir de uma avaliação qualitativa, sendo este valor diretamente proporcional ao nível de influência, ou seja, quanto maior o índice menor o grau de proteção, conforme proposta do trabalho de Ross (1994). Vale ressaltar que foi verificada a coerência dos resultados com as observações de campo (validação).

O mapa de fragilidade ambiental (Eq. 1) foi obtido a partir de cruzamento dos atributos: precipitação pluviométrica, substrato rochoso, declividade, solo e uso e ocupação do solo, conforme segue:

$\mathrm{FA}=([\mathrm{PP}]+[\mathrm{SR}]+[\mathrm{D}]+[\mathrm{S}]+[\mathrm{UO}]) / 5$

Em que:

FA: fragilidade ambiental

PP: precipitação pluviométrica

SR: substrato rochoso

D: declividade

S: solo

UO: uso e ocupação do solo

Tendo em vista que os graus de fragilidade ambiental foram calculados pelo somatório dos valores atribuídos a cada grau de fragilidade de um determinado atributo selecionado, e que os valores dos atributos hierarquizados não foram necessariamente números inteiros, tornou-se necessário agrupar os valores obtidos em intervalos de cinco graus de fragilidade, como pode ser observado na Tab. 1.

A geração dos mapas procedeu ao desenvolvimento de rotinas para a conversão de dados vetoriais em formato matricial (raster), com tamanho de célula de $30 \mathrm{~m}$. Posteriormente foi utilizada a opção raster calculator do ArcGis Desktop 9.3 para o desenvolvimento das operações de álgebra de mapas. A escala cartográfica adotada foi de 1:100.000.

PRECIPITAÇÃO PLUVIOMÉTRICA Face à variação pluviométrica verificada na área de estudo, em que se observam três diferentes domínios pluviométricos, levou-se em consideração esta variável para a análise da fragilidade natural. Foram estabelecidos níveis hierárquicos (Tab. 2) de acordo com a maior ou menor intensidade do efeito pluviométrico sobre os processos morfodinâmicos (Crepani et al. 2004). Com isso, os comportamentos pluviométricos obedeceram a uma hierarquização de ordem crescente quanto à capacidade de interferência na estabilidade do ambiente.

SUBSTRATO ROCHOSO A resistência à erosão das rochas que compõem uma unidade de paisagem natural é consequência de seu grau de coesão. Segundo Crepani et al. (2001), grau de coesão das rochas significa a intensidade da ligação entre os minerais ou partículas que as constituem. Nesse sentido, considerou-se na análise o grau de fragilidade representado pelo grau de coesão dos minerais da rocha em cada unidade mapeada. Desta maneira, as litologias mais antigas do embasamento cristalino receberam valor entre 2,2 e 2,7; os sedimentos do Grupo Barreiras representam uma situação intermediária, com valor 3; as formações de idade Cretácea receberam valores entre 4,2 e 4,7; e aos sedimentos inconsolidados Quaternários foi atribuído valor 5 (Tab. 3).

DECLIVIDADE Para se estabelecer as classes de declividade foram utilizados intervalos (Tab. 4) já consagrados nos estudos de capacidade de uso/aptidão agrícola associados a valores conhecidos de limites críticos da Embrapa (2006). A declividade do terreno apresenta-se como um importante fator a ser analisado no mapeamento da fragilidade ambiental, pois os processos erosivos

Tabela 1-Intervalos dos graus de fragilidade ambiental

\begin{tabular}{lc}
\hline Classe & Grau de fragilidade \\
\hline Muito baixa & $1 \mathrm{a} \leq 1,5$ \\
\hline Baixa & $1,5 \mathrm{a} \leq 2,5$ \\
\hline Média & $2,5 \mathrm{a} \leq 3,5$ \\
\hline Alta & $3,5 \mathrm{a} \leq 4,5$ \\
\hline Muito alta & 4,5 a 5 \\
\hline
\end{tabular}

Tabela 2 - Graus de fragilidade para o atributo precipitação pluviométrica

\begin{tabular}{lc}
\hline Classes climáticas & Grau de fragilidade \\
\hline Aw & 2 \\
\hline Am & 2,3 \\
\hline Af & 2,5 \\
\hline
\end{tabular}

Aw: clima tropical com estação seca de inverno; Am: clima de monção; Af: clima tropical úmido. 
podem ser acelerados em função do grau de inclinação de uma vertente, fornecendo boa aproximação para as questões referentes à erosão que ocorre em uma bacia hidrográfica.

SOLO A resistência dos solos aos processos erosivos é consequência de suas características, tais como textura, estrutura, porosidade, permeabilidade, consistência e profundidade. Elas definem a maior ou menor susceptibilidade do solo aos processos erosivos, o que justifica a importância desta variável para estabelecer a fragilidade do ambiente.

Nas áreas onde ocorrem solos estáveis foi atribuído o valor de fragilidade 1 (Tab. 5). Esta classe é representada pelos latossolos, ou seja, solos bem desenvolvidos, profundos, com boas propriedades físicas (permeáveis, porosos, friáveis e de baixa plasticidade).

Já nas áreas onde ocorre a classe dos argissolos atribuiu-se valor 2. Quando comparados aos latossolos, eles apresentam profundidade menor, são menos estáveis e menos intemperizados. Ocorrem em topografia um pouco mais dissecada e a diferença de textura entre os horizontes A e B dificulta a infiltração de água em seus perfis, favorecendo o processo erosivo.

Os cambissolos e luvissolos foram caracterizados como solos intermediários, sendo atribuídos valores de fragilidade de 3 e 3,5, respectivamente.

Nas áreas em que ocorrem solos mais frágeis, a exemplo dos espodossolos, neossolos, gleissolos e organossolos, foram atribuídos valores de fragilidade entre 4 e 5 . De forma geral, esses são solos jovens e pouco desenvolvidos, com horizonte A assentado diretamente sobre o horizonte $\mathrm{C}$ ou sobre a rocha mãe (não possuem horizonte $\mathrm{B}$ ), com lençol freático superficial.
USO E OCUPAÇÃO DO SOLO Para estabelecer as classes de fragilidade para os diferentes tipos de uso e ocupação do solo levou-se em consideração o papel da vegetação como manto protetor da paisagem (Nascimento \& Dominguez 2009). A cobertura vegetal responde pela estabilidade dos processos morfodinâmicos. Desta forma, quanto mais densa é a cobertura vegetal maior é a capacidade de frear o desencadeamento de processos mecânicos da morfogênese. A baixa energia para a remoção de material e transporte favorece os processos pedogenéticos enquanto restringe os morfogenéticos. Por outro lado, a falta de cobertura florestal densa contribui para a instabilidade ambiental, com o desenvolvimento da morfogênese (Tricart 1977).

Tabela 4-Graus de fragilidade para o atributo declividade

\begin{tabular}{lc}
\hline Classes de declividade (\%) & Grau de fragilidade \\
\hline$<3$ & 1 \\
\hline $3-8$ & 2 \\
\hline $6-20$ & 3 \\
\hline $20-45$ & 4 \\
\hline$>45$ & 5 \\
\hline
\end{tabular}

Tabela 5-Graus de fragilidade para o atributo solo*

\begin{tabular}{ll}
\hline Classes de solo & Grau de fragilidade \\
\hline Latossolos & 1 \\
\hline Argissolos & 2 \\
\hline Cambissolos & 3 \\
\hline Luvissolos & 3,5 \\
\hline Espodossolo / neossolos & 4 \\
\hline Gleissolos / organossolos & 5 \\
\hline
\end{tabular}

* Para cálculo da média ponderada dos casos que possuem 2 associações de solos, foi adotado o seguinte critério: $60 \%$ grau de fragilidade $+40 \%$ grau de fragilidade $=$ grau de fragilidade final; para casos com 3 associações: $50 \%$ grau de fragilidade + $30 \%$ grau de fragilidade $+20 \%$ grau de fragilidade $=$ grau de fragilidade final.

Tabela 3 - Graus de fragilidade para o atributo substrato rochoso

\begin{tabular}{lc}
\hline Classes de substrato rochoso & Grau de fragilidade \\
\hline Complexo Ibicaraí - gnaisses granulitizados & 2,2 \\
\hline Complexo Almadina - granulitos, quartzitos e bandas metabásicas intercaladas & 2,2 \\
\hline Granitoides Ibirapitanga-Ubaitaba - granitoides & 2,2 \\
\hline Suíte intrusiva Itabuna - Sienito & 2,3 \\
\hline Complexo São José - rochas magmáticas granulitizadas & 2,5 \\
\hline Rochas metabásicas & 2,7 \\
\hline Grupo Barreiras & 3 \\
\hline Formação Sergi - siltitos, arenitos e conglomerados & 4,2 \\
\hline Formação Itaparica - folhelhos, siltitos e arenitos & 4,5 \\
\hline Grupo Ilhas - arenitos, folhelhos e siltitos & 4,5 \\
\hline Formação Urucutuca - folhelhos e siltitos & 4,7 \\
\hline Formação Candeias - folhelhos e siltitos & 4,7 \\
\hline Depósitos Aluvionares - areias, siltes, argilas e cascalhos & 5 \\
\hline Depósitos Flúvio-Lagunares - siltes, argilas e materiais orgânicos & 5 \\
\hline Terraços marinhos - areias com minerais pesados & 5 \\
\hline
\end{tabular}


Na Tab. 6 apresentam-se os valores de fragilidade atribuídos a cada tipo de uso e ocupação do solo.

Desta maneira, de acordo com os critérios estabelecidos por Tricart (1977) e Nascimento \& Dominguez (2009), foram adotados os valores mais baixos, entre 1 e 2, para os terrenos protegidos que apresentam maior densidade da cobertura vegetal, enquanto as classes Restinga e Pastagem/Cultivo de subsistência receberam valores entre de 3 e 4 , respectivamente, considerando a baixa densidade de cobertura. As classes Área úmida, Área urbana e Solo exposto foram consideradas de alto grau de fragilidade ambiental, justificando a atribuição do valor máximo 5 .

\section{Análises físico-químicas da água Para a ob-} tenção dos dados físico-químicos da água, foram realizadas cinco campanhas para coleta de água superficial no período de julho de 2009 (inverno), dezembro de 2009 (primavera), janeiro de 2010 (verão), março de 2010 (outono) e julho de 2010 (inverno), a fim de detectar, em estações diferentes, variações sazonais na qualidade da substância encontrada na bacia em estudo.

Foram escolhidos 12 pontos de amostragem ao longo do Rio Almada, procurando-se a seleção de pontos de fácil acessibilidade à montante e à jusante dos principais centros urbanos, com vistas à avaliação do impacto causado pelo lançamento de efluentes domésticos e industriais e dos diversos usos do solo na bacia, além da influência da contribuição de afluentes. Priorizou-se, ainda, a escolha de pontos localizados sob pontes, com o objetivo de possibilitar a coleta de amostras representativas no centro do curso d'água. Os pontos de amostragem foram ordenados no sentido da nascente à foz e estão representados na Fig. 2.

Os parâmetros físico-químicos $\mathrm{pH}$, temperatura da água e condutividade elétrica foram determinados in situ, enquanto os sólidos totais e turbidez foram determinados em laboratório (Eaton et al. 2005). A Tab. 7 apresenta as técnicas e os equipamentos utilizados. Ressalta-se que, na primeira campanha, não foram obtidos os dados de sólidos totais e turbidez.

Tabela 6 - Graus de fragilidade para o atributo uso e ocupação

\begin{tabular}{ll}
\hline Classes de uso e ocupação & Grau de fragilidade \\
\hline Floresta de Mata Atlântica & 1 \\
\hline Cabruca & 2 \\
\hline Restinga & 3 \\
\hline Pastagem e cultivo de subsistência & 4 \\
\hline Áreas úmidas / área urbana / solo exposto & 5 \\
\hline
\end{tabular}

Foi realizado também o levantamento dos índices pluviométricos na região, bem como das vazões do Rio Almada em duas estações fluviométricas localizadas em Itajuípe e Ilhéus, a fim de avaliar a influência da sazonalidade sobre os resultados.

\section{Delimitação da área de contribuição dos pontos de amostragem Determinou-se a área de} drenagem que contribui para cada ponto amostrado calculando-se as porcentagens dos níveis de fragilidade ambiental em cada uma destas áreas.

Foram delimitadas as sub-bacias da BHRA, obtidas de forma automática pelo programa Soil and Water Assessment Tool (SWAT) no ambiente ArcGis. Neste processo, utilizaram-se como banco de dados as imagens de radar SRTM/Topodata $30 \mathrm{~m}$, cujos divisores topográficos são interpretados gerando um modelo numérico topográfico e de rede de drenagem com fluxo de acumulação e direção. Posteriormente foi definida a área mínima de delimitação de 10 mil ha. Assim, o programa distribui pontos exutórios, ou seja, pontos de um curso d'água nos quais se acumula todo o escoamento superficial gerado no interior da sub-bacia, a partir do qual a sub-bacia é delimitada (Di Luzio et al. 2001).

Tendo em vista que nem todas as sub-bacias possuem pontos de amostragem e que os existentes não estavam localizados na foz das sub-bacias correspondentes, procedeu-se à delimitação das 12 áreas de contribuição compostas pelas sub-bacias que, total ou parcialmente, influenciam na qualidade da água de cada ponto de coleta.

\section{RESULTADOS E DISCUSSÃO}

Fragilidade ambiental A fragilidade ambiental muito baixa (Fig. 3) é a de menor representação na bacia $(0,1 \%)$, totalizando $15,75 \mathrm{~km}^{2}$, e está localizada em fragmentos bem preservados de mata, baixas declividades, domínio dos argissolos (fragilidade baixa) e sobre as rochas do embasamento cristalino (fragilidade baixa).

As áreas de grau de fragilidade ambiental baixa são as mais representativas $(75,2 \%)$, correspondendo a $1.178 \mathrm{~km}^{2}$. O alto valor percentual desta classe deve-se aos fatos de que $66,1 \%$ da área da bacia estão localizados em declives menores que $20 \%$, considerados de baixa a média fragilidade; $86 \%$ dela são compostos por rochas do embasamento cristalino, as quais apresentam menor fragilidade quando 


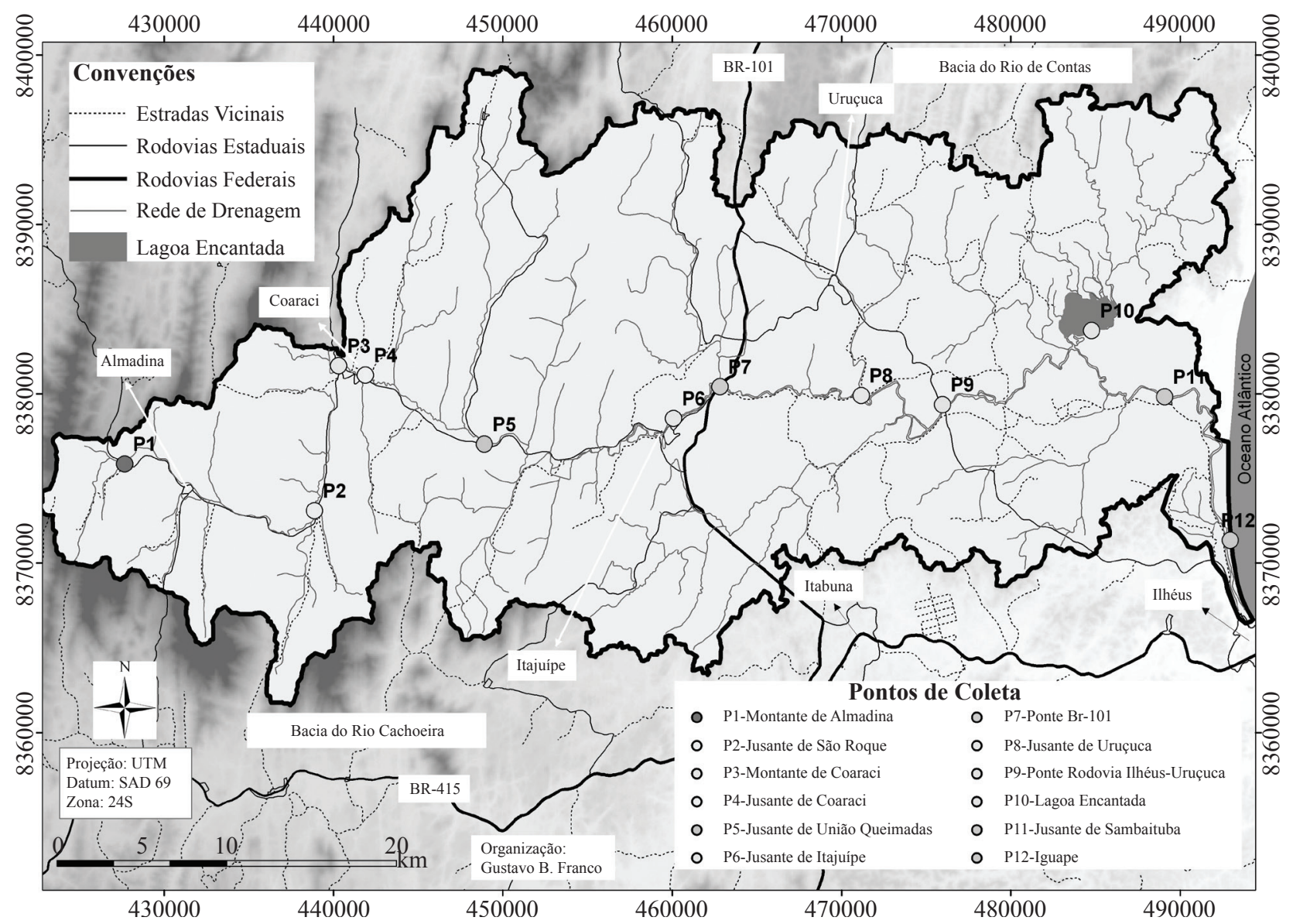

Figura 2 - Localização dos pontos de amostragem de água na Bacia Hidrográfica do Rio Almada.

Tabela 7 - Técnicas analíticas, principais materiais e metodologias utilizadas nas análises de qualidade da água

\begin{tabular}{|c|c|c|c|}
\hline Parâmetro & Técnica analítica & Equipamento / reagentes / meio de cultura & Método e/ou referência \\
\hline Temperatura & - & \multirow{3}{*}{ pHmetro / condutivímetro OAKTON WD-35630-69 } & APHA 2550 \\
\hline $\mathrm{pH}$ & Potenciometria & & APHA $4500-\mathrm{H}^{+}$ \\
\hline Condutividade elétrica & Condutivimetria & & APHA 2510 B \\
\hline Sólidos totais & Gravimetria & $\begin{array}{l}\text { Estufa Nova Técnica NT 512, balança Quimis, membrana de } \\
\text { fibra de vidro Schleicher \& Schuell GF 52-C Ø47 mm }\end{array}$ & APHA 2540 B \\
\hline Turbidez & Nephelometria & Turbidímetro Hach 2100 AN & APHA 2130 B \\
\hline
\end{tabular}

comparadas com as das Bacia Sedimentar, Grupo Barreiras e os Depósitos Quaternários; há baixa diferenciação entre os índices pluviométricos que definem os três domínios a que a bacia está submetida, sendo estes relacionados ao grau de fragilidade baixo; os solos de fragilidade muito baixa e baixa cobrem cerca de $89,1 \%$ do total; e o uso e ocupação do solo de fragilidade muito baixa e baixa representam $77,9 \%$ da BHRA.

As áreas de grau de fragilidade médio cobrem $294 \mathrm{~km}^{2}$, ou seja, 18,8\% da área total, sendo o segundo grau de fragilidade dominante na área. Esta classe distribui-se por toda a bacia ao longo das calhas de drenagem e estradas, concentrando-se nas porções Oeste e Leste da bacia aos redores das áreas de fragilidade alta.

A fragilidade ambiental alta é a terceira classe mais representativa na BHRA, presente em 5,9\% da área total, correspondendo a $87,3 \mathrm{~km}^{2}$. Observa-se, na Fig. 3, que o grau de fragilidade ambiental alto distribui-se nas áreas urbanas, no extremo Oeste da bacia, em virtude do processo de ocupação por pastagens, maiores declividades, solos de fragilidade média (luvissolos) e na porção Leste e litorânea em função da baixa fragilidade do substrato rochoso, solo e uso e ocupação do solo. Destaca-se na zona costeira a presença dos ecossistemas mais sensíveis da região, sujeitos às inundações e onde os riscos de contaminação também são elevados.

Analisando outras pesquisas que identificaram áreas de fragilidade ambiental em bacias hidrográficas, nota-se que a BHRA apresenta baixas concentrações de áreas com grau de fragilidade ambiental alto $(5,9 \%)$ e nenhuma área de grau muito alto, em 
comparação a outros somatórios de percentuais de fragilidade ambiental alta e muito alta. É possível citar como exemplo os estudos realizados por Spörl (2001) nas altas bacias do Rio Jaguari-Mirim, Ribeirão do Quartel e Ribeirão da Prata (a Nordeste do Estado de São Paulo e ao Sul de Minas Gerais). Esta autora aplicou três metodologias na mesma região, tendo encontrado valores de $10,4,44,87$ e 58,57\% de áreas com fragilidade ambiental alta e muito alta. Kawakubo et al. (2005), no Córrego Onofre (SP), definiram 40\%; Mello (2008), na bacia hidrográfica do Rio Verde (SP), 22\%; Padilha (2008), no Rio Arroio Grande (RS), 28,59\%; e Santos (2008), na Bacia do córrego Bebedouro (MG), 31,78\%.

Mesmo considerando que as características ambientais de cada bacia hidrográfica são peculiares e as metodologias aplicadas diferentes, nota-se que a BHRA, diante das características já apresentadas, a exemplo das vastas áreas cobertas por floresta, apresenta valores pequenos de fragilidade ambiental alta, fato que reforça a importância de preservação ambiental para que não haja aumento das áreas de grau alto e surgimento de outras de grau muito alto.

\section{Avaliação da qualidade da água Os da-} dos pluviométricos mensais monitorados na estação
LE-CL-01 (INGÁ 2010), ilustrados na Fig. 4, permitem a visualização da distribuição de chuvas durante todo o período de amostragem. Os valores de vazões monitoradas nas estações fluviométricas (Tab. 8) acompanharam os índices observados na bacia. Os números evidenciam vazões significativamente menores nas campanhas ocorridas em dezembro de 2009 e janeiro de 2010, bem como nos índices pluviométricos registrados nesses meses, em relação às demais. Os maiores valores foram verificados nos meses de julho.

Os resultados obtidos para os parâmetros analisados são apresentados na forma de gráficos (Figs. 5 a 9). No caso dos parâmetros que têm

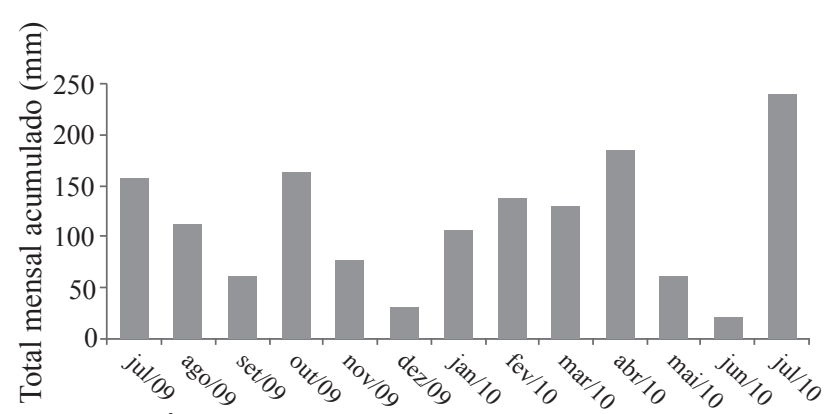
Fonte: INGÁ 2010.

Figura 4-Totais pluviométricos mensais acumulados no periodo de monitoramento.

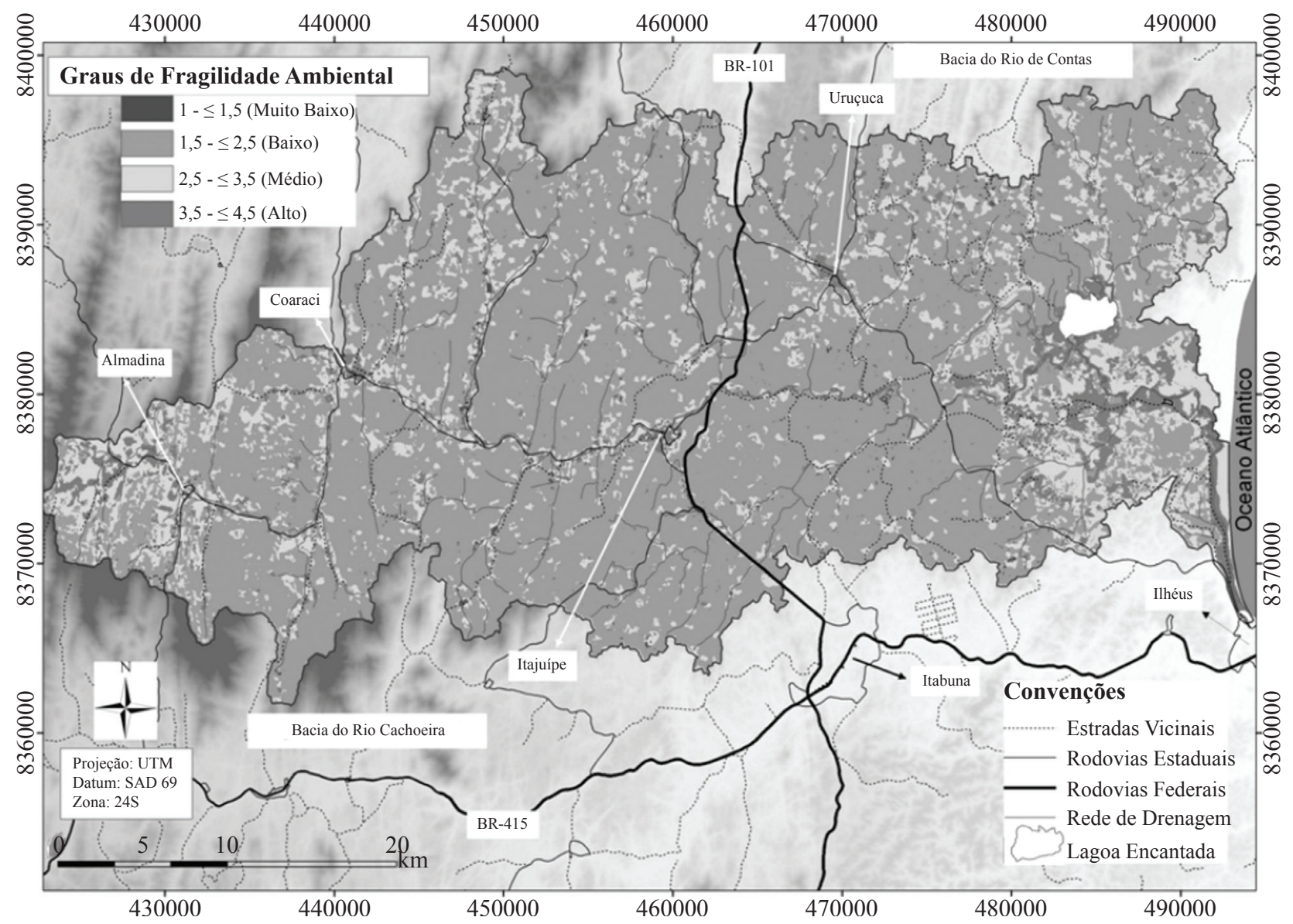

Figura 3 - Distribuição dos graus de fragilidade ambiental da Bacia Hidrográfica do Rio Almada. 
padrão legal estabelecido na Resolução CONAMA 357/05 (Brasil 2005), foram adicionados aos gráficos os limites, a fim de ilustrar com clareza as não-conformidades.

Os resultados do parâmetro temperatura da água (Fig. 5) variaram de $33,4^{\circ} \mathrm{C}$ a $22,0^{\circ} \mathrm{C}$, sendo as médias dos valores na primeira, segunda, terceira, quarta e quinta campanhas respectivamente de 24,$5 ; 30,2$; 28,$3 ; 28,7$ e $24,6^{\circ} \mathrm{C}$. Assim, os resultados obedeceram à variação sazonal anual, tendo sido menor na primeira e na quinta campanhas, que ocorreram em julho, quando as temperaturas médias diárias foram menores.

Os valores de $\mathrm{pH}$ (Fig. 6) variaram entre 6,02 e 7,89, sendo os mais elevados ocorridos nos pontos $\mathrm{P} 1, \mathrm{P} 10$ e P12. No P1 e P12 foram observadas maiores concentrações, de modo geral, dos elementos $\mathrm{Na}$, $\mathrm{Mg}$ e $\mathrm{Ca}$ - $\mathrm{Ca}$ e $\mathrm{Mg}$ estão normalmente associados à presença de carbonatos e bicarbonatos, bases responsáveis pela alcalinidade da água, ou seja, à capacidade de neutralização de acidez, o que justifica os maiores valores de $\mathrm{pH}$ nesses pontos em relação aos demais da bacia. Valores de $\mathrm{pH}$ maiores no ponto
P10 podem estar relacionados à maior atividade fotossintética nesse local, onde foram observados valores elevados de oxigênio dissolvido e algumas colônias de algas. Nos relatórios do Programa Monitora foram relatados resultados não conformes de clorofila e Índice de Estado Trófico supereutrófico no ponto de monitoramento da Lagoa Encantada, representando alta produtividade fitoplanctônica (INGÁ 2009). De acordo com König et al. (1999), a elevada atividade fotossintética realizada pelas algas pode remover $\mathrm{CO}_{2}$ do meio mais rapidamente que sua reposição pela atividade bacteriana, levando ao aumento dos valores de $\mathrm{pH}$.

Com relação à condutividade elétrica, observou-se grande variação nos resultados (Fig. 7), que apresentaram valor máximo de $9.960,0 \mu \mathrm{S}_{\mathrm{cm}}{ }^{-1} \mathrm{e}$ mínimo de $53,0 \mu \mathrm{S} . \mathrm{cm}^{-1}$. Os maiores valores foram observados nos pontos P1 e P12, justificados pelas maiores concentrações de íons nesses locais, especialmente dos metais alcalinos $\mathrm{Na}^{+}$e $\mathrm{K}^{+}$e alcalinos terrosos $\mathrm{Mg}^{++}$e $\mathrm{Ca}^{++}$, os quais possuem elevada correlação com esse parâmetro (Margalef 1983). No

Tabela 8 - Vazões mensais nas estações fluviométricas no período de estudo

\begin{tabular}{|c|c|c|c|c|}
\hline \multirow{2}{*}{$\begin{array}{l}\text { Estação } \\
\text { Ano }\end{array}$} & \multicolumn{2}{|c|}{ Itajuípe (53050000) - Itajuípe } & \multicolumn{2}{|c|}{ Provisão II (53091000) - Ilhéus } \\
\hline & Mês & Vazão $\left(\mathrm{m}^{3} \cdot \mathrm{s}^{-1}\right)$ & Mês & Vazão $\left(\mathrm{m}^{3} \cdot \mathrm{s}^{-1}\right)$ \\
\hline \multirow{6}{*}{2009} & Julho & 5,0904 & Julho & 14,7005 \\
\hline & Agosto & 5,1112 & Agosto & 14,8748 \\
\hline & Setembro & 2,3562 & Setembro & 6,3813 \\
\hline & Outubro & 7,4154 & Outubro & 12,0497 \\
\hline & Novembro & 3,2735 & Novembro & 4,6872 \\
\hline & Dezembro & 0,4299 & Dezembro & 0,0173 \\
\hline \multirow{7}{*}{2010} & Janeiro & 0,4931 & Janeiro & 0,0172 \\
\hline & Fevereiro & 0,9132 & Fevereiro & 0,1256 \\
\hline & Março & 1,9799 & Março & 0,7223 \\
\hline & Abril & 8,6612 & Abril & 38,0233 \\
\hline & Maio & 0,7511 & Maio & 0,0603 \\
\hline & Junho & 0,3110 & Junho & 0,0182 \\
\hline & Julho & - & Julho & 20,2299 \\
\hline
\end{tabular}

Fonte: ANA (2012).

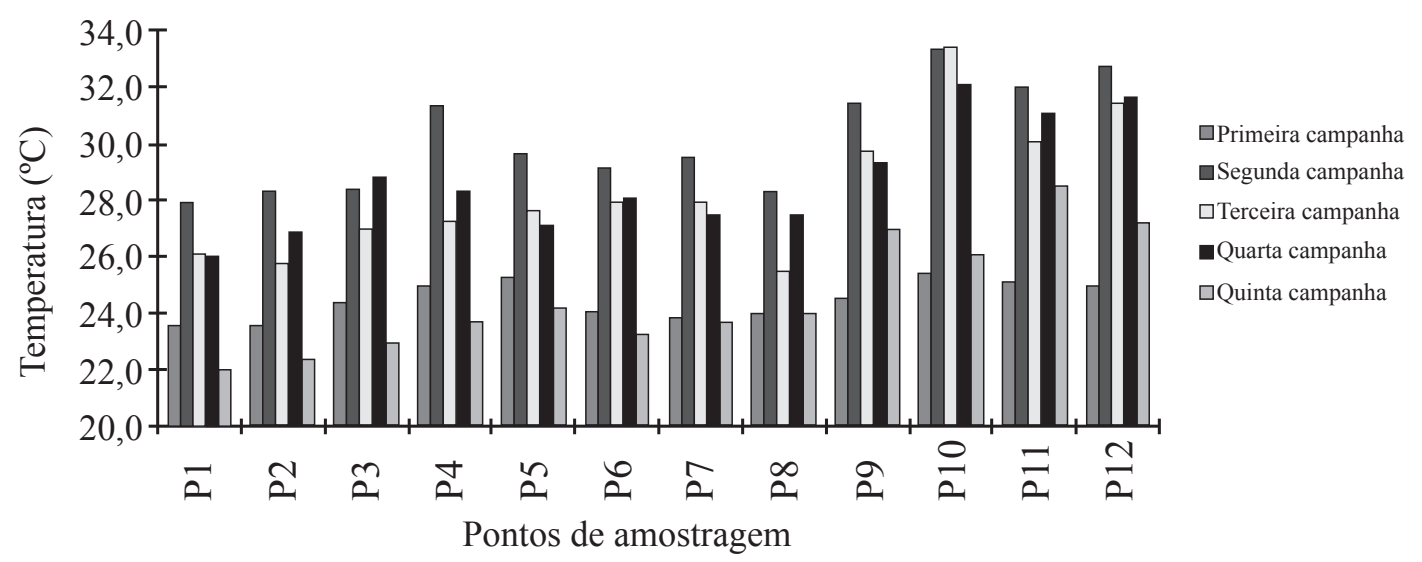

Figura 5 - Resultados do parâmetro "temperatura da água" nos pontos de amostragem. 
ponto $\mathrm{P} 1$, tais resultados podem estar relacionados às características dos solos da região, marcados pela presença de luvissolos crômicos, que são solos eutróficos caracterizados por alta saturação por bases. Já no P12, próximo ao mar, os teores elevados desses elementos relacionam-se à influência da salinidade, já que as concentrações de íons, especialmente sódio, são muito elevadas.
Os valores de sólidos totais (Fig. 8) variaram entre $18.590,0$ e 40,0 mg.L - $^{-1}$ e apresentaram comportamento determinado pelas concentrações de sólidos dissolvidos totais. Os maiores valores observados foram nos pontos P12 e P1, nos quais também ocorreram maiores variações ao longo das campanhas.

Os valores do parâmetro turbidez (Fig. 9) variaram de 20,70 UNT a 1,96 UNT e apresentaram

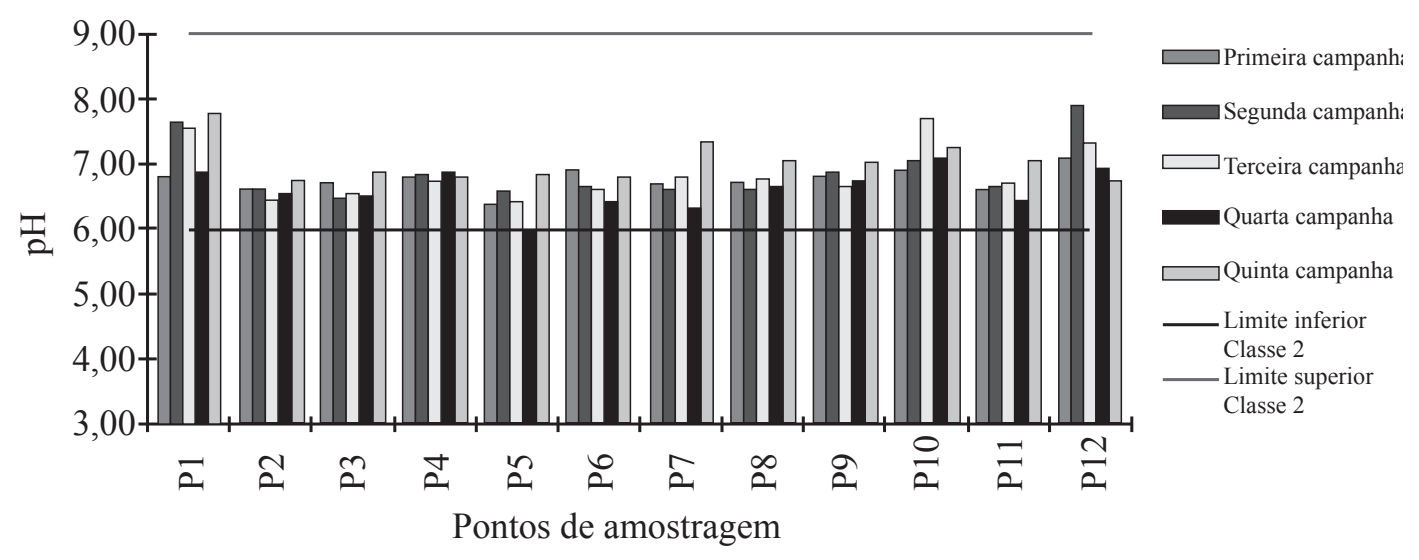

Figura 6-Resultados do parâmetro " $p H$ " nos pontos de amostragem.

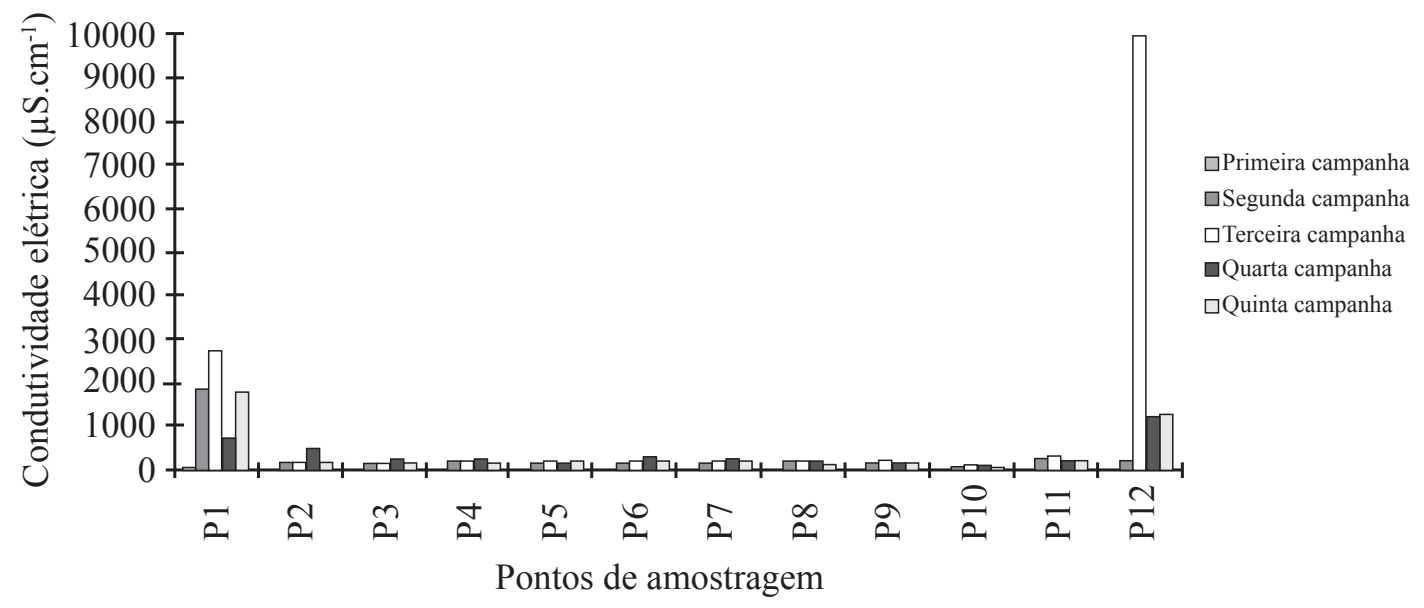

Figura 7 - Resultados do parâmetro "condutividade elétrica” nos pontos de amostragem.

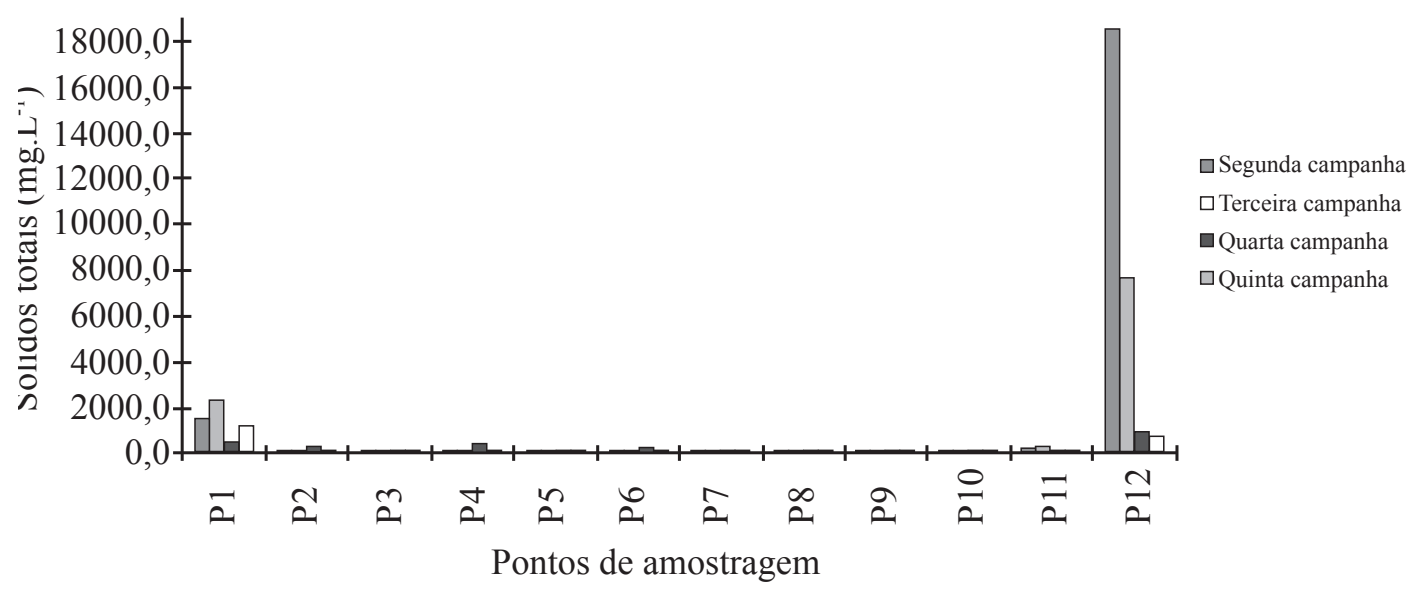

Figura 8-Resultados do parâmetro “sólidos totais” nos pontos de amostragem. 
média igual a 6,23 UNT, não havendo, de modo geral, grande variação entre os pontos. Os resultados foram maiores na quarta campanha em relação às demais. O ponto onde ocorreram maiores variações foi o P1, talvez devido à grande susceptibilidade à erosão dos solos desta região Oeste da bacia, pois se trata de uma área onde predominam pastagens degradadas com indício de erosão laminar.

Criação do IQAFA O IQAFA procurou integrar os parâmetros físico-químicos (variáveis resposta) da água que estariam mais relacionados com os graus de fragilidade da bacia de contribuição. Para tanto, adaptou-se o Índice de Qualidade da Água (IQA), desenvolvido pela National Sanitation Foundation (NSF), dos Estados Unidos, em 1970, composto por nove parâmetros (E. coli, $\mathrm{pH}$, demanda bioquímica de oxigênio, nitrato, fosfato, temperatura, turbidez, sólidos totais e oxigênio dissolvido), considerados mais representativos para a caracterização da qualidade das águas (Von Sperling 2007).

O índice foi definido a partir de cinco parâmetros, sendo eles: temperatura, condutividade elétrica, $\mathrm{pH}$, sólidos totais e turbidez. Uma premissa básica da proposição do índice é que ele deveria ser de fácil reprodutibilidade por pesquisadores de todo o país.

A cada parâmetro foi atribuído um peso $\left(\mathrm{w}_{\mathrm{i}}\right)$ de acordo com a sua importância relativa no cálculo do IQAFA: 0,05 (temperatura), 0,15 (condutividade elétrica), $0,20(\mathrm{pH}), 0,25$ (sólidos totais) e 0,35 (turbidez).

O IQAFA é calculado como um produto das notas individuais de cada parâmetro, elevadas aos respectivos pesos. O cálculo dos valores de $\mathrm{q}_{\mathrm{i}}$ foi feito a partir das médias dos resultados. O valor do índice varia de 0 a 100 (Eq. 2).

$I Q A F A=\prod q^{i} w^{i}$
Em que:

IQAFA: índice de qualidade da água em resposta à fragilidade ambiental

$\mathrm{q}_{\mathrm{i}}$ : qualidade do i-ésimo parâmetro, um número entre 0 e 100, obtido por meio de fórmulas em função de sua concentração ou medida

$\mathrm{w}_{\mathrm{i}}$ : peso do i-ésimo parâmetro, um número de 0 a 1 , atribuído em função da sua importância para a conformação global de qualidade

i: número do parâmetro, variando de 1 a 5

A condutividade elétrica é o único parâmetro não considerado e parametrizado originalmente no IQA. Logo, para a sua inserção nos cálculos do IQAFA foram obtidas funções de primeiro grau para o cálculo de $q_{\mathrm{i}}$ via regressão linear (Tab. 9), considerando os intervalos de valores de condutividade elétrica frente ao risco de salinização do solo (Bernardo 1995), uma vez que não existe legislação que estabeleça limites para esse parâmetro segundo outros critérios, como, por exemplo, adequação para consumo humano.

Assim, a partir do cálculo do IQAFA, foram definidos os níveis de qualidade do corpo hídrico (Tab. 10). Depois de caracterizada numericamente, a qualidade da água é definida por faixas, sendo que, à medida que diminui o valor do índice, a qualidade se deteriora.

Tabela 9 - Funções lineares para obtenção de qualidade do parâmetro "condutividade elétrica", numa escala de 0 a 100

\begin{tabular}{lc}
\hline $\begin{array}{l}\text { Valores de condutividade elétrica } \\
(\mu \mathrm{S} / \mathrm{cm})\end{array}$ & Funções lineares \\
\hline $0 \mathrm{a}<250$ & $\mathrm{Y}=-0,04 \mathrm{x}+100$ \\
\hline $250 \mathrm{a}<750$ & $\mathrm{Y}=-0,03 \mathrm{x}+97,5$ \\
\hline $750 \mathrm{a}<2250$ & $\mathrm{Y}=-0,00167 \mathrm{x}+87,5$ \\
\hline $2250 \mathrm{a}<5000$ & $\mathrm{Y}=-0,0073 \mathrm{x}+66,364$ \\
\hline$\geq 5000$ & $\mathrm{y}=30$ \\
\hline
\end{tabular}

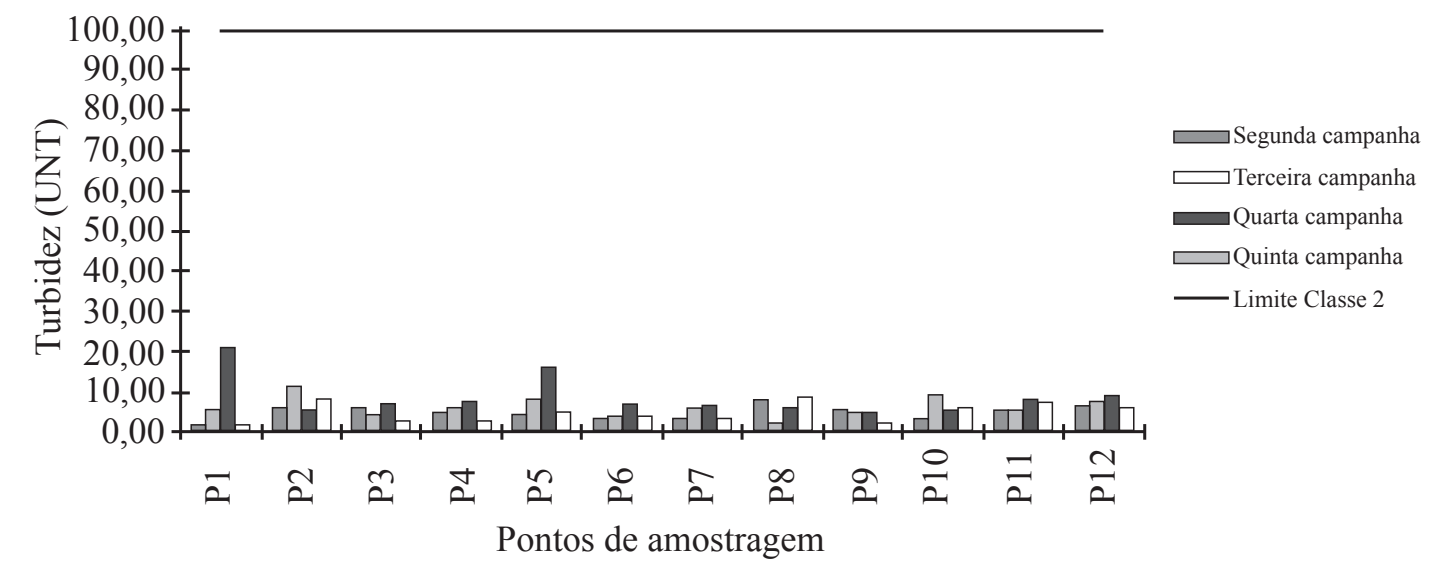

Figura 9 - Resultados do parâmetro "turbidez" nos pontos de amostragem. 
Os valores do IQAFA foram relacionados à fragilidade ambiental nas áreas de influência de cada ponto de amostragem, delimitadas como descrito no item "Delimitação da área de contribuição dos pontos de amostragem".

Validação do IQAFA Para validação do IQAFA estabeleceu-se uma relação com o percentual das áreas de fragilidade ambiental baixa e alta das áreas de contribuição do ponto de amostragem (Tab. 11). Nota-se que os menores percentuais de fragilidade ambiental baixa correspondem às áreas de contribuição $1(28,9 \%)$ e $12(26,6 \%)$, que apresentam menores valores de IQAFA de 61,4 (Regular) e 59,1 (Regular), respectivamente; assim como os maiores percentuais de fragilidade ambiental alta correspondem a estas mesmas áreas de contribuição $1(23,7 \%)$ e $12(29,8 \%)$.

As demais (2 a 11) apresentaram de 60,1 a $91,5 \%$ de suas áreas com fragilidade ambiental baixa e de 0,5 a 13,9\% alta, e IQAFA variando entre 78,2 e $86,6 \%$, sendo enquadrado na categoria Bom.

A maior quantidade de área de fragilidade ambiental alta evidencia maiores áreas degradadas com grande potencial de erosão, gerando perda da qualidade físico-química da água, como ratificado pelos resultados do IQAFA.

$\mathrm{O}$ índice apresentou elevada correlação $\left(\mathrm{R}^{2}=0,8604\right)$ com a fragilidade ambiental baixa, indicando que quanto maiores as áreas de fragilidade baixa, menor a perda da qualidade físico-química da água. A correlação do IQAFA com a fragilidade alta também foi elevada $\left(\mathrm{R}^{2}=0,8248\right)$, apontando que quanto maiores as áreas de fragilidade alta, maior a perda da qualidade físico-química da água.

\section{CONCLUSÕES}

A BHRA apresenta poucas áreas com fragilidade ambiental alta e ausência de áreas com fragilidade ambiental muito alta. Contudo, é importante ressaltar que a fragilidade ambiental determinada reflete a atual, pois à medida que há mudança de uso e ocupação na bacia altera-se o grau de fragilidade em função da dinâmica de ocupação, requerendo, portanto, constantes atualizações dos dados como condição necessária à utilização em anos consecutivos. Este processo de atualização deve permitir o monitoramento das áreas frágeis bem como cadastrar e analisar outras que venham a surgir.

Apesar da subjetividade da criação deste índice, a validação do IQAFA demonstrou que a escolha dos parâmetros usados para o cálculo foi adequada, uma vez que as alterações da qualidade das águas refletiram a presença de áreas com menor ou maior valor de fragilidade ambiental.

Assim sendo, o IQAFA torna-se uma ferramenta para o planejamento e gerenciamento ambiental de bacias hidrográficas, sendo adequado na compreensão da situação da qualidade da água frente à fragilidade ambiental.

Tabela 10 - Classificação da qualidade da água segundo o Índice de Qualidade da Água em Resposta à Fragilidade Ambiental

\begin{tabular}{lc}
\hline Classe & Faixa de IQAFA \\
\hline Ótima & $90<$ IQAFA $\leq 100$ \\
\hline Boa & $70<$ IQAFA $\leq 90$ \\
\hline Regular & $50<$ IQAFA $\leq 70$ \\
\hline Ruim & $30<$ IQAFA $\leq 50$ \\
\hline Péssima & $0<$ IQAFA $\leq 30$ \\
\hline
\end{tabular}

IQAFA: Índice de Qualidade da Água em Resposta à Fragilidade Ambiental.

Tabela 11 - Contribuição percentual de áreas de fragilidade ambiental média e alta e classificação dos valores de Índice de Qualidade da Água em Resposta à Fragilidade Ambiental da Bacia Hidrográfica do Rio Almada

\begin{tabular}{|c|c|c|c|c|}
\hline \multirow{2}{*}{ Área de contribuição } & \multicolumn{2}{|c|}{ Valor de área de fragilidade ambiental (\%) } & \multirow{2}{*}{ Valor IQAFA } & \multirow{2}{*}{ Classe } \\
\hline & Baixo & Alto & & \\
\hline 1 & 28,9 & 23,7 & 61,4 & Regular \\
\hline 2 & 67,4 & 7,8 & 79,3 & Boa \\
\hline 3 & 77,6 & 3,6 & 84,4 & Boa \\
\hline 4 & 81,6 & 6,9 & 83,5 & Boa \\
\hline 5 & 78 & 1,6 & 78,2 & Boa \\
\hline 6 & 86,6 & 2 & 84,2 & Boa \\
\hline 7 & 86,2 & 1,2 & 85,3 & Boa \\
\hline 8 & 82,1 & 3 & 83,8 & Boa \\
\hline 9 & 91,5 & 0,5 & 86,6 & Boa \\
\hline 10 & 68 & 7,8 & 86,6 & Boa \\
\hline 11 & 60,1 & 13,9 & 80,9 & Boa \\
\hline 12 & 26,6 & 29,8 & 59,1 & Regular \\
\hline
\end{tabular}

IQAFA: Índice de Qualidade da Água em Resposta à Fragilidade Ambiental. 
Acredita-se que estudos voltados para melhoria do processo de análise e interpretação da qualidade água versus fragilidade ambiental possam surgir, de modo a agregar um conjunto de indicadores ambientas e de avaliação dos efeitos de contribuição da poluição difusa.
AGRADECIMENTOS Ao apoio financeiro do Conselho Nacional de Desenvolvimento Científico e Tecnológico (CNPq) (Processo $n^{\circ}$ 576937/2008-8) e ao Departamento de Ciências Agrárias e Ambientais da Universidade Estadual de Santa Cruz (UESC), pela logística laboratorial e de campo.

\section{Referências}

Agência Nacional das Águas (ANA). 2012. Estações da ANA. Disponível em: http://www.ana.gov.br/ portalsnirh/Esta\%C3\%A7\%C3\%B5esdaANA/ tabid/359/Default.aspx. Acessado em: 04/04/2012.

Arcanjo J.B.A., Oliveira J.E., Gomes R.A.A.D., Meneses N.R.F., Teixeira L.R., Souza J.D., Padilha A.V., Delgado I.M., Santos R.A., Melo R.C., Fernandes P.C.A. 1997. Programa del Levantamentos geológicos básicos do Brasil, Itabuna, Folha SD-24-Y-B-VI. Brasília, CPRM, v. 1, 276 p.

BAHIA. Secretaria de Recursos Hídricos, Saneamento e Habitação. Superintendência de Recursos Hídricos. 1996. Plano diretor de recursos hídricos - Bacias do Leste. Salvador, Higesa, 155 p.

Barbosa J.S.F. \& Dominguez J.M.L. (eds.) 1996. Geologia da Bahia: texto explicativo para o mapa geológico ao milionésimo. Salvador, SICM/SGM, 400 p.

Bernardo S. 1995. Manual de irrigação. Viçosa, Imprensa Universitária, $657 \mathrm{p}$.

BRASIL. Ministério das Minas e Energia. 1981. Projeto Radambrasil. Salvador-Folha SD24, VI 24: Geologia, Geomorfologia, Pedologia, Vegetação e Uso Especial da Terra. Rio de Janeiro, Ministério das Minas e Energias, $623 \mathrm{p}$.

BRASIL. Resolução no. 357, de 17 de março de 2005. Dispõe sobre a classificação dos corpos de água e diretrizes ambientais para o seu enquadramento bem como estabelece condições e padrões de lançamento de efluentes e dá outras providências. Disponível em: $<$ http:// http://portal.saude.gov.br/portal/arquivos/pdf/ resolucao_conama357.pdf > . Acessado em: 15/09/2009.

Carvalho Filho R., Melo A.A.O. de, Santana S.O. de, Leão A.C. 1987. Levantamento semidetalhado dos solos do município de Ilhéus. Ilhéus, CEPLAC, Boletim Técnico 147, $84 \mathrm{p}$.

Crepani E., Medeiros J.S. de, Hernandez P., Florenzano T.G., Duarte V., Barbosa C.C.F. 2001. Sensoriamento remoto e geoprocessamento aplicados ao zoneamento ecológico-econômico e ao ordenamento territorial. São José dos Campos, SAE/INPE, 124 p.

Crepani E., Medeiros J.S., Palmeira A.F. 2004. Intensidade pluviométrica: uma maneira de tratar dados pluviométricos para análise da vulnerabilidade de paisagens à perda de solo. São José dos Campos, INPE, 92 p.

Di Luzio M., Srinivasan R., Arnold J. 2001. Arcliew interface for SWAT2000 - User's guide. Texas, Blackland Research Center, 337 p.
Eaton A.D., Clesceri L.S., Rice E.W., Greenberg A.E., Franson M.A.H. (eds.) 2005. Standard methods for the examination of water and wastewater. Washington, APHA, $1000 \mathrm{p}$.

Empresa Brasileira de Pesquisa Agropecuária (EMBRAPA). 2006. Sistema brasileiro de classificação de solos. Rio de Janeiro, Embrapa, 306 p.

Franco G.B. 2010. Fragilidade ambiental e qualidade da água na Bacia do Rio Almada - Bahia. Tese de Doutorado, Departamento de Engenharia Civil, Universidade Federal de Viçosa, Viçosa, 345 p.

Gomes F.H. 2002. Caracterização de solos de manguezais e de restinga no município de Ilhéus-Bahia. Dissertação de Mestrado, Departamento de Solos, Universidade Federal de Viçosa, Viçosa, 96 p.

Instituto de Gestão das Águas (INGÁ). 2008. Programa monitora. Relatório anual de 2009. Salvador, SEMA, 39 p.

Instituto de Gestão das Águas(INGÁ). Dadospluviométricos. Disponível em: http://sistemas.inga.ba.gov.br/sistemas/ planilhas/plu/. Acesso em: 01/10/2010.

Kawakubo F.S., Morato R.G., Campos K.C., Luchiari A., Ross J.L.S. 2005. Caracterização empírica da fragilidade ambiental utilizando geoprocessamento. In: Simp. Bras. de Sensoriamento Remoto, 12, Anais, p. 2203-2210.

König A., Souza M.S.M., Costa N.A.F., Freitas V.L.B., Ceballos B.S.O. 1999. Variação nictemeral da qualidade do efluente final de uma lagoa facultativa secundária e a influência das algas. In: Associação Brasileira de Engenharia Sanitária e Ambiental. Desafios para o saneamento ambiental no terceiro milênio. Rio de Janeiro, ABES, p. 1-10.

Margalef R. 1983. Limnologia. Barcelona, Ediciones Omega, $952 \mathrm{p}$.

Mello J.P. de. 2008. Ensaio cartográfico para a determinação da fragilidade ambiental na bacia hidrográfica do Rio Verde (SP). Dissertação de Mestrado, Instituto de Geociências, Universidade Estadual de Campinas, Campinas, $120 \mathrm{p}$.

Melo A.A.O. de. 1985. Levantamento dos solos do município de Uruçuca.Ilhéus, CEPLAC, Boletim Técnico 129, $53 \mathrm{p}$.

Nascimento D.M.C. \& Dominguez J.M.L. 2009. Avaliação da vulnerabilidade ambiental como instrumento de gestão costeira nos municípios de Belmonte e Canavieiras, Bahia. Revista Brasileira de Geociencias, 39:395-408. 
Padilha D.G. 2008. Geoprocessamento aplicado na caracterização da fragilidade ambiental da bacia hidrográfica do Arroio Grande, RS. Dissertação de Mestrado, Departamento de Matemática, Universidade Federal de Santa Maria, Santa Maria, 86 p.

Richter R. 2000. Atmosferic correction algorithm for flat terrain: ATCOR2. Washington, Geosystems, 208 p.

Roeder M. 1975. Reconhecimento climatológico. Diagnóstico socioeconômico da região Cacaueira. Rio de Janeiro, IICA/CEPLAC, 89 p.

Ross J.L.S. 1994. Análise empírica da fragilidade dos ambientes naturais e antropizados. Revista do Departamento de Geografia, 8:3-74.

Santana S.O. de, Melo A.A.O. de, Leão A.C. 1986. Levantamento semidetalhado dos solos do município de Itajuípe. Itabuna, CEPLAC, Boletim Técnico 142, 48 p.

Santana S.O. de, Melo,A.A.O.de, LeãoA.C. 1987.Levantamento semidetalhado dos solos do município de Lomanto Júnior, Bahia. Ilhéus, CEPLAC, Boletim Técnico 153, 39 p.

Santos C.R. 2008. Diagnóstico ambiental e uma proposta de uso da bacia hidrográfica do córrego Bebedouro - Uberlândia/MG. Dissertação de
Mestrado, Instituto de Geografia, Universidade Federal de Urbelândia, Uberlândia, 117 p.

Santos H.G. dos, Hochmuller D.P., Cavalcanti A.C., Rego R.S., Ker J.C., Panoso L.A., Amaral J.A.M. 1995. Procedimentos normativos de levantamentos pedológicos. Brasília, Embrapa-SPI. 116 p.

Santos R.D., Lemos R.C., Santos H.G., Ker J.C., Anjos L.H.C. 2005. Manual de descrição e coleta de solo no campo. Viçosa, SBCS, 92 p.

Spörl C. 2001. Análise da fragilidade ambiental relevo-solo com aplicação de três modelos alternativos nas altas bacias do Rio Jaguari-Mirim, Ribeirão do Quartel e Ribeirão da Prata. Dissertação de Mestrado, Departamento de Geografia, Universidade de São Paulo, São Paulo, 166 p.

Tricart J. 1977. Ecodinâmica. Rio de Janeiro, IBGE/ SUPREN, $91 \mathrm{p}$.

Von Sperling M. 2007. Estudo e modelagem da qualidade da água de rios. Belo Horizonte, UFMG, 588 p.

Manuscrito ID 20995

Recebido em: 11/03/2011

Aprovado em: 01/08/2012 